\title{
Quieting the mind: aspects of neuroscience in reconciliation
}

\section{Michael Tophoff ${ }^{1}$}

\section{Abstract}

The reconciliation of conflicting parties by the mediator has to deal with high levels of emotional arousal. She or he has to lower these levels for reconciliation to succeed. In this paper two approaches to accomplish this and to quiet the mind are presented, a Buddhist one (anapanasati) and a Western one (Mindfulness-Based Stress Reduction, commonly known as MBSR).

In order for the mediator to comprehend emotional arousal and the practices of quieting the mind, some underlying aspects of neuroscience are discussed, specifically, the prefrontal cortex and the limbic system. In contrast to mindfulness-based stress reduction, anapanasati, in its definition of mindfulness as well as in its practice, seems compatible with neuroscience. Recommendations are made to the mediator to facilitate the process of reconciliation.

\section{Introduction}

In establishing interpersonal peace processes, the bridging and transcending of the 'I versus thou' paradigm, one of the foremost causal factors in conflict, is of fundamental importance to the mediator. The more the person identifies with herself in a complete attachment, the more distant, sometimes even hostile, the other becomes. Here, the basis for suffering is built.

Causally, conflicts also arise from craving for what we want for ourselves and what we don't get. In the Buddhist view, conflicts arise from what is held dear,

\footnotetext{
${ }^{1}$ I am thankful to Professor André van der Braak (Dept. of Theology and Religion, Vrije Universiteit Amsterdam) for his challenging ideas.
} 
which arises from longing (Batchelor, S., 2011). In the Buddha's words: "Longing arises from what is pleasant and unpleasant in the world" (Norman, 2001. p114). If something is pleasant, we long to have it. If something is unpleasant, we want to get rid of it.

Reconciliation is one of the main preconditions for peace. In order to reconcile the parties involved, conflicts first have to be worked through. These conflicts, interpersonal as well as intergroup, always entail high levels of emotional arousal (Mischel et.al, 2014). Conflicting parties nearly always experience strong emotions like stress, anger, frustration, hopelessness, depression - in Buddhist terms ' unwholesome states' ${ }^{2}$. These emotions tend not only to fuel conflicts but also make for their escalation. They are the foremost hindrances for reconciliation.

Frequently, in the practice of conflict reconciliation, at least three persons are involved: the two conflicting parties and the mediator who tries to reconcile them. The conflicting parties may not be the only ones to show high levels of arousal: the mediator may become overinvolved and overcompassionate ${ }^{3}$. High levels of emotional arousal are incompatible with reconciliation. Being overly involved emotionally, the mediator will not be able to calmly oversee this process and to intervene adequately. She or he has to lower their own levels of emotional arousal first. Reconciling conflicting parties requires calm and a quiet mind to resolve the issues being debated.

Quieting the mind, however, by lowering levels of arousal, is not an easy endeavour. The mediator not only has to quiet their mind, they also have to be able to calm down their clients. Towards this end, a variety of methods have been proposed, in both non-Buddhist (Sandy, S. V., 2014) and Buddhist circles (Thanissaro Bhikkhu, 2014).

This paper does not focus on the process of reconciliation per se, since this has been done extensively elsewhere (Coleman, P.T., et al (eds.) 2014). Here, the

\footnotetext{
2 Unwholesome states point to actions like greed, anger, hatred and delusion, leading to rebirths with harmful experiences in them (Harvey, 2000, p44).

${ }^{3}$ The risks of being over-compassionate are described in Bloom, P. (2016).
} 
focus is on quieting the mind as a precondition for reconciliation. Towards this end, two approaches will be discussed: a Buddhist practice (anapanasati) and a Western psychological practice (Mindfulness-Based Stress Reduction: MBSR). Both practices are centred around mindfulness.

The term mindfulness is problematic. It is not easily defined and such definitions as exist vary considerably (Dreyfuss, G. 2013). Mindfulness, in the Buddhist Abhidharma ${ }^{4}$ sense, is based on the Pali concept of sati, (Skrt.: smrti). This is defined as 'recollection', namely of the Buddha's teaching (Soothill and Hodous, 1937), as a recollection of the Buddha5: Buddhanussmrti (Williams, P., 2009, p209), or as to remember to maintain awareness (Batchelor, 2011, quoted by Grossman and van Dam, 2013, p220). Here, mindfulness is not a personality trait, but a practice mentioned in the Satipatthana-Sutta (Grossman and van Dam, 2013, p221). This is a practice of retentive focus, which cognitively implies discriminating ${ }^{6}$ and holding an object within the dimensions of past and future, so that we can recollect it later (Dreyfuss, 2013). Dreyfuss comments lucidly:

"The practice $(\ldots)$ is not the goal but a means $(\ldots)$ its main point is not to obtain a calm and focused state, however helpful such a state may be $(. .$.$) but to free our minds from the habits (...) that bind us to$ suffering" Dreyfuss (2013, p51) (my italics).

This calm and focused state does indeed seem to be helpful as a precondition for reconciliation for all of the parties involved, since it may contribute to a significant lowering of arousal levels. It is for this reason that this paper focuses on the Buddhist practice of anapanasati meditation. It is a meditation practice involving the 'four frames of reference': body, feeling, mind and mental objectives. The meditator may focus on the awareness of in-and-out breathing, calming bodily fabrications (Thanissaro Bhikkhu, 2014). In fact, however, this is only the first phase in a process designed eventually to lead to ending suffering and to liberation.

\footnotetext{
${ }^{4}$ Abhidharma, the 'higher teaching', early Buddhist texts compiled between 3rd c B.C.E. and 3rd c C.E.

5 Siddharta Gotama, 563-483 B.C.E.

${ }^{6}$ See also Sharf's (2013) challenging paper.
} 
This paper also discusses a Western psychological practice, the Mindfulnessbased Stress Reduction, developed by Kabat-Zinn and others (Williams, MG., 2013). Here, mindfulness is presented as "a tool for regulating the emotions" (Bizzini, 2011, p132) and mindfulness is defined as a meditation practice to cultivate present-centred awareness in a non-judgmental way (Kabat-Zinn, 2003; Ludwig and Kabat-Zinn, 2008).

Based on this definition of mindfulness, a training procedure, called Mindfulness-Based Stress Reduction, has been developed for meditation practice to foster stress reduction and emotion management (Bishop, 2002). It consists of a combination of sitting meditation, body scan, yoga exercises and homework assignments assisted by auxiliary audio tapes. The format includes " $8-10$ weekly group sessions, with one session being a full day retreat" (Bishop, 2002, p72).

In order to comprehend emotional arousal and the practices of quieting the mind, it is imperative to first look deeper into the nature of arousal as well as into the mechanisms that govern these practices, which involve neurophysiological processes within neuroanatomical structures of the human brain. This paper therefore highlights some neurophysiological and neuroanatomical foundational aspects of mindfulness, in their creative dialectics.

Specifically, the question is critically discussed whether or not the Buddhist method for quieting the mind (anapanasati) ${ }^{7}$ and the Western method of Mindfulness Based Stress Reduction are compatible with what is known from neuroscience as regards their respective definitions of mindfulness and their practices. Further, if they are in fact compatible, the question of whether or not they are valid tools in lowering arousal levels in reconciliation by the mediator is discussed. Finally, ways for facilitating reconciliation are examined.

\footnotetext{
7 Although in this paper anapanasati is described as a means to 'calming bodily fabrication' (Thanissaro Bhikkhu (tr.), 2014, 3/6), this has to be seen as only one phase in the wider context of this practice of the monastic way to end suffering.
} 


\section{The foundation of mindfulness: creative dialectics}

Looking at neuroanatomical foundations of mindfulness, one could conceive of the brain as a metaphor for the Buddhist concept of impermanence.

Impermanence (anitya) is one of the so-called marks of existence: all phenomena are interdependently in flux (Waldron, 2017). Within the brain there is a creative dialectic of arising and ceasing, of incoming and outgoing, of reciprocal contact of higher and lower regions, such as, for example between the prefrontal cortex and limbic system, between the limbic system and still lower regions such as the brain stem (medulla oblongata).

Likewise, there is a dialectic between the sympathetic nervous system (which is directed towards action, as in the flight, fight and freeze response) on the one hand, and the parasympathetic nervous system (making for calm and rest) on the other. This ever-changing system, characterised by neuroplasticity and its processes have been lucidly and profoundly described by Austin (Austin, 1998 passim, 2006, 2011). His monumental work will guide us in the descriptions below, while we point to some of his hypotheses concerning the functioning of the limbic system and the prefrontal cortex.

In view of the fluidity of the brain and the vast 'white spaces' in our knowledge, there is a multitude of reasons to be cautious when interpreting experimental studies on mindfulness meditation and brain processes - they seldom lead to stable conclusions which can be generalised (Bishop, S. R., 2002; Dreyfuss, G. 2013; Grossman, P. and van Dam, N.T., 2013). Another reason for caution in interpreting results, is the set-up of an experiment using such things as electrodes or a PET scan, which influences the awareness of the subject. Methodological as well as psychometrical errors abound (Grossman, P. and van Dam, N.T., 2013).

Discussing the aspects of neuroscience which are relevant for mindfulness, meditation practices may nevertheless facilitate our understanding and evaluation of them, in spite of reservations and justified objections about 'scientific research' in the field of mindfulness. To aim to study Buddhist concepts and, specifically, 
Buddhist practices such as anapanasati with scientific - that is neurological or neuro-electrical means - would place them within the realm of science, albeit a 'science of the mind'. Buddhism, on the contrary, is not a science and should not pretend to be one. Buddhism "involves a spiritual or idealist conception (...) the supposed Buddhist ideal - Awakening - is resolutely supra-mundane and nonsecular" (Faure, 2009, p104).

Keeping these words of caution in mind, what kind of neuroanatomical and neurophysiological foundations of mindfulness are we talking about? In this paper, first, the limbic system will be briefly described, second, the prefrontal cortex since they are the most relevant brain structures for mindfulness.

\section{The limbic system}

The limbic system controls emotions, behaviour and memory and processes, one could say, the Buddhist 'unwholesome states'. Its main components are: hippocampus, thalamus, hypothalamus and amygdala.

\section{The hippocampus}

The hippocampus, with pathways into the frontal lobes, hypothalamus and amygdala, 'codes', so to say, our incoming sensory information. It infuses this information with memories which are developed there. It connects and integrates incoming stimuli directly with experiences from the past. In this way, it attributes meaning to incoming information. It structures it with past experiences, fears, and anxieties. Incoming stimuli are not perceived by a tabula rasa (blank page) brain. The retinal perception is processed and flooded with memory imaging by the Hippocampus. In experiences such as trauma, loss of a beloved one and pain, the Hippocampus plays a crucial role. Chronic stress damages the Hippocampus and leads to memory loss (Austin, 1998, p185).

\section{The thalamus}


The thalamus is located deep in the centre of the brain. It is a relay station, having a powerful connecting function within the limbic system. Pathways connect with lower positioned inner brain structures, and with the hippocampus as well as with the prefrontal cortex. Visual stimuli pass via the retina into the thalamus. There they are processed and emotionally 'coloured' before they are sent up to consciousness.

\section{The hypothalamus}

The hypothalamus is located below the thalamus and above the brain stem. In itself it is a rather small organ, weighting only 4 grams. It plays a fundamental role in neurophysiological processes like fear and stress. It functions in an 'automatic' evolutionary way essential for survival. All mammals share this very same function. This means, that even in adult humans with a mature prefrontal cortex ${ }^{8}$, these very mechanisms are active in situations of stress. In mindfulness meditations, fears, anxieties, memories and stress responses come to the surface. It is important, therefore, to focus, albeit briefly, on these processes.

The stress response proceeds via two pathways: neural and hormonal. On the neural pathway the incoming signal (e.g. a tiger) activates the hypothalamus, which relays these signals in fractions of seconds to the spinal cord (not to the prefrontal cortex!), activating the sympathetic nervous system to respond either with flight, fight or freeze (FFF).

The hormonal route, ultimately, has the same effect as the neural one, strengthening indeed the FFF response. Here, the incoming signal (e.g. a tiger) triggers activity in the hypothalamus, which in his turn activates the pituitary gland (the hypophysis), stimulating the adrenal cortex to produce cortisol, the 'stress hormone', leading to FFF. One of the effects of cortisol is the prevention of blood flow to the prefrontal cortex. In this way, rational thinking is automatically disabled (Arnsten, 2010).

8 In humans, the prefrontal cortex only matures around the age of 23. 


\section{The amygdala}

The amygdala consists of two almond-shaped clusters located deep within the temporal lobes. It has a primary role in the processing of attention and emotions. It is an evaluating system, deciding instantly whether a stimulus is noxious or not. If it is noxious, the genetically programmed, evolutionary fundamental FFF mechanisms are triggered. Its right side in particular seems to be associated with fear and anger as well as with memories which are emotionally 'coloured'.

There seems to be a strong relationship between amygdala and breathing, between breathing and emotion. Homma, J., and Masaoka Y. (2008) point to findings that show more rapid breathing during a state of arousal. In this context, Austin (Austin 1998, p178) states: "In breathing in, many Amygdala cells discharge. While exhaling, only half of that number fires (...) Expiration quiets down the firing of the Amygdala" (my italics). Markowitsch and Staniloiu (2010, p718) point to the Amygdala's function for the processing of autobiographical events; they state "Given its contribution to the integration of emotion, perception and cognition (including memory for past autobiographical events) the Amygdala also forges the establishment and maintenance of an integrated self."

\section{The prefrontal cortex}

The prefrontal cortex, the most sophisticated part of the central nervous system, in the words of Austin, 1998, p256) "distances us from our environment". The prefrontal cortex helps to avoid getting overwhelmed and overruled by the signals from the limbic system, from which it continuously receives massive amounts of information. Sensory input is coded here into processes of cognition and decision making while processing and scanning of sensate messages takes place subcortically. Here, our behaviours are monitored and fine-tuned. Sensate information is cognitively transformed into meaningful wholes, which it may then integrate into sequences of meaning. The prefrontal cortex is based in the frontal lobe. Here, our instinctual impulses seem to be socialised and cognitively 
evaluated. Three major regions are involved: the orbital prefrontal cortex, the medial prefrontal cortex and the dorsolateral prefrontal cortex.

The orbital prefrontal cortex is positioned horizontally behind the eye sockets. Intricately connected with the limbic system, it controls impulses and drives, specifically those deemed unsociable and thus undesirable. It seems also to weigh up the consequences of actions before we actually engage in them or not, depending on the 'intensity' of the impulse load.

The medial prefrontal cortex seems mainly to process action-oriented behaviours. The emphasis within these actions is intentional as well as attentional. In this way, these behaviours point to future-oriented actions.

The dorsolateral prefrontal cortex occupies the largest part of the prefrontal cortex. This part is much less connected with subcortical systems. Probably it plays a major role not only in attributing and infusing meaning to sensations but also to organise these within cognitive contexts.

\section{Discussion}

In the light of the information presented above, let us now look critically at the earlier-mentioned definitions of mindfulness and at the validity of their two practices.

\section{The anapanasati practice}

Within an abhidharma constructivist perspective, based on the definition of sati as recollection, Dunne (2011) points to the proper intentional training and to the effort that is needed in meditation as mindfulness practice. Dreyfuss (2013) describes a cognitive-evaluative and thus distinctive quality in the definition of mindfulness. He specifies 'Wise Mindfulness' (Dreyfuss, 2013, p51) as integrating retention with clear comprehension. He emphasises mindfulness as a holding of an 
object, including memories, and as future-oriented in attributing meaning to the object:

"Mindfulness is then not the present-centred non-judgmental awareness of an object but the paying close attention to an object, leading to the retention of the data so as to make sense of the information delivered by our cognitive apparatus. Thus, far from being limited to the present and to a mere refraining from passing judgment, mindfulness is a cognitive activity closely connected to memory, particularly to working memory, the ability to keep relevant information active so that it can be integrated within meaningful patterns and used for goal directed activities" (Dreyfuss, 2013, p47).

In sharp contrast to a concept of the brain as a tabula rasa (blank sheet) and to 'bare awareness', the function of the mature brain of the adult is fully equipped for the function of abhidharma-defined anapanasati meditation. The creative dialectics of prefrontal cortex and of the limbic system allow fully for a cognitive, intentional processing of all the coded sensate information reaching the frontal lobes. Mindfulness of in-and-out breathing, with the emphasis on the outbreath, reduces amygdala arousal and quiets the mind, as in the words of the Buddha:

"There is the case where a monk, having gone to the wilderness, to the shade of a tree, or to an empty building, sits down folding his legs crosswise, holding his body erect, and setting mindfulness to the fore. Always mindful, he breathes in; mindful he breathes out. (...) He trains himself, 'I will breathe in calming bodily fabrication.' He trains himself, 'I will breathe out calming bodily fabrication. Breathing in long, he discerns, 'I am breathing in long'; or breathing out long, he discerns, 'I am breathing out long.' Or breathing in short, he discerns, 'I am breathing in short'; or breathing out short, he discerns, 'I am breathing out short.' "(Thanissaro Bhikkhu, tr., 2014; see also Hanh, 2013)

Anapanasati, as mindfulness of breathing, is a valid practice for lowering high levels of arousal. The mediator may practice mindfulness of breathing - with 
the emphasis on the outbreath - before and even during the mediation session. Likewise, as we will point out later in this paper, she or he may assist their clients by teaching them this form of mindfulness to prepare them for reconciliation. Anapanasati, in its full spiritual significance, will be discussed in the concluding recommendations below.

\section{Mindfulness-Based Stress Reduction}

Mindfulness-Based Stress Reduction (MBSR) is based on a definition of mindfulness as present-centred and non-judgmental. In view of the knowledge of neuroscience, this definition is senseless. As we have seen, all sensate information being processed in the limbic system either projects into lower regions of the brain to - neurologically and hormonally - activate sympathetic nervous pathways for flight, fight or freeze or this information is 'sent up' to the prefrontal cortex, being already fully saturated and infused with past memories, future expectations, hopes and fears, and judgments coloured with attributed meaning. There is no such thing as a (more than momentary) present-centredness, nor is there nonjudgmentality.

A stress-reduction technique based on false premises is problematic. However, according to practitioners of this technique, a massive body of research is presented to corroborate its validity and usefulness (cfr. Ludwig, D.S., and Kabat-Zinn, J., 2008; Williams, J. M.G. and Kabat-Zinn, J. 2013). Interventions such as Mindfulness-Based Stress Reduction produce clinically significant results in depression, pain and stress reduction according to Baer (2013). However, we already urged caution when researchers present their results on mindfulness practice as scientific facts. Even when more sophisticated tests such as the reversed-score-items technique are used, they are still psychometrically unconvincing, since they harbour a multitude of methodological errors and bias (Grossman, P. and Van Dam, N.T., 2013). In view of all of this, Mindfulness-Based Stress Reduction does not seem a feasible practice for quieting the mind.

\section{Concluding recommendations}


In focusing on the actual practice of reconciliation, the different roles of the persons involved - mediator and conflicting parties - have to be considered. As regards the two (or more) persons in a situation of conflict, they need a formula that is relatively easy and directly applicable if their emotional levels are to be eased. Toward this end, anapanasati breathing practice can be useful. Mindful breathing, the awareness of in-breath and awareness of out-breath, slows down breathing, making it deeper (Hanh, 2013). The mediator will profit from mindful breathing not only in preparing him or herself mentally for the session, but also during mediation itself as soon as they become aware of emotional overinvolvement. She or he may teach the practice to their clients at the outset of reconciliation and all three may practice at those moments when emotional arousal recurs ${ }^{9}$.

As to the mediator as a professional, though profiting from mindful breathing practice, they will need much more intensive training and study in order to be maximally effective in her role. Their role is essential to peace-making, to establishing degrees of harmony where first there was conflict. Their motive for being a mediator may well be to end suffering of the parties involved. This position may be linked to the Buddhist bodhisattva:

"whose task is to compassionately help beings (...) in his wisdom he knows that there are no 'beings' ${ }^{10}$. (Reconciling) wisdom with compassion he works for the salvation of all beings, which experience themselves as suffering." (Harvey, 2000, p121) Within this context, however, mindfulness meditation goes far beyond a lowering of emotional arousal. Ultimately, it "has a motivating agenda: the desire for Awakening, which is classed not as a cause of suffering, but as part of the path to its ending." (Thanissaro Bhikkhu, 2000)

\footnotetext{
${ }^{9}$ Mindfulness-Based Stress Reduction would not be recommended for the conflicting parties. First, as shown, it is based on questionable premises and research, second because the programme requires at least several weeks of practice.

${ }^{10}$ Because he has transcended the 'I versus thou' paradigm.
} 


\section{References}

Arnsten, A.F.T. (2009). Stress signaling pathways that impair prefrontal cortex structure and function. In: National Revue of Neuroscience, 10, 6, 410-422 Austin, J.H. (1998) Zen and the Brain. Cambridge: M.I.T. Press. Austin, J.H. (2006) Zen Brain Reflections. Cambridge: M.I.T. Press. Austin, J.H. (2011) Selfless Insight. Cambridge: M.I.T Press. Baer, R. A. (2013). Measuring Mindfulness. In: Williams, J . M. G., Kabat-Zinn (Eds. ). (2013) Mindfulness, Diverse Perspectives on its meaning, Origins and Applications. New York: Routledge, 241-261.

Batchelor, S. (2011). Secular Buddhism. New Haven: Yale University Press. Bishop, S. R. (2002). What do we really know about Mindfulness-Based Stress Reduction? Psychosomatic Medicine, 64: 71-84 Bizzini, L. B. (2011) Mindfulness in the Treatment of Depression. In: Fraser, A. (Ed.). The Healing Power of Meditation. Boston \& London: Shambala, 128-139. Bloom, P. (2016). Against Empathy: The Case for Rational Compassion. New York: Harper Collins.

Coleman, P.T., Deutsch, M. and Marcus, E.C. (Eds.) (2014) The Handbook of Conflict Resolution. San Francisco: J ohn Wiley \& Sons Inc Dunne, J. (2011). Towards an understanding of non-dual mindfulness. Contemporary Buddhism, Vol.12, 1: 71-88

Dreyfuss, G. (2013). Is Mindfulness present-centered and non-judgmental? In: Williams, J.M.G. and Kabat-Zinn (Eds.). (2013) Mindfulness, Diverse Perspectives on its meaning, Origins and Applications. New York: Routledge, 41-54.

Faure, B. (2009). Unmasking Buddhism. Oxford: Wiley-Blackwell Grossman, P. and van Dam, N.T. (2013). Mindfulness by any other Name...Trials and Tribulations of SATI in Western Psychology and Science. In: Williams, J . M. G. , Kabat-Zinn (Eds. ). (2013) Mindfulness, Diverse Perspectives on its meaning, Origins and Applications. New York: Routledge, 219-239.

Hanh, T.N. (2013). Zen Battles: Modern Commentary on the Teachings of Master Linji. New York: Broadway Books.

Harvey, P. (2000). An Introduction to Buddhist Ethics. Cambridge: Cambridge University Press. 
Homma, J . and Masaoka, Y. (2008). Breathing Rhythms and Emotions.

https:// doi.org/ 10.1113/ expphysiol. 2008. 042424

Kabat-Zinn, J . (2003). Mindfulness-Based Interventions in Context: Past, Present and Future. Clinical Psychology, 10, 2, 144-156

Ludwig, D.S. and Kabat-Zinn, J. (2008). Mindfulness in Medicine. J AMA, 300 (1), 1350-1352

Markowitsch, H.J ., and Staniloiu A. "Amygdala in action: Relaying biological and social significance to autobiographical memory," Neuropsychologia, 2011; 49 (4): 718-733

Mischel, W., De Smet, A.L and Kross, E. (2014). Self-Regulation in the Service of Conflict Resolution. in: Coleman, P.T. , Deutsch, M., and Marcus, E.C. (Eds.) (2014) The Handbook of Conflict Resolution. San Francisco: J ohn Wiley \& Sons Inc. Norman, K. R. (tr) (2001). The Group of Discourses (Sutta Nipata). Oxford: Pali Text Society.

Sandy, S. V. (2014) The Development of Conflict Resolution Skills, in: Coleman, P.T.., Deutsch, M., and Marcus, E.C. (Eds.) (2014) The Handbook of Conflict Resolution. San Francisco: J ohn Wiley \& Sons Inc Sharf, R. (2013). Mindfulness and Mindlessness in early Chan. In: Philosophy East \& West Volume 64, Number 4 October (2014) 933-964 933 @ 2014 by University of Hawaii Press.

Soothill, W.E. and Hodous, R. (1937). A Dictionary of Chinese Buddhist Terms. London: Kegan Paul.

Thanissaro Bhikkhu (tr.) (2014). Anapanasati Sutta: Mindfulness of Breathing. http:// www. accesstoinsight. org/tipitaka/ mn/mn.118. than. html Waldron, W. S. (2017). Reflections on Indian Buddhist Thought and the Scientific Study of Meditation. In: McMahan, D.L. and Braun, E. (2017) Meditation, Buddhism, and Science. New York: Oxford University Press, 84-114.

Williams, P. (2009). Mahayana Buddhism: The Doctrinal Foundations. New York: Routledge.

Williams, J . M.G. and Kabat-Zinn (Eds. ). (2013) Mindfulness, Diverse Perspectives on its meaning, Origins and Applications. New York: Routledge. 
Michael M Tophoff, PhD, is a clinical psychologist-psychotherapist who received his doctorate at the University of Utrecht. He teaches Conflict Management at the University of Amsterdam Business School. Currently he is studying for a Master of Theology and Religion. 